\title{
DOE/CE/15604-. T8
}

FP8THRPT

\author{
COAL AIR TURBINE "CAT" PROGRAM \\ INVENTION 604
}

BY

R. W. FOSTER-PEGG

EIGHTH QUARTER PROJECT REPORT AND FINAL FOR THE PROJECT

(August-September 1996)

SEPTEMBER 30, 1996

Hit 


\section{DISCLAIMER}

Portions of this document may be illegible in electronic image products. Images are produced from the best available original document. 


\section{"CAT" PROJECT INVENTION 604 \\ QUARTERLY REPORT TABLE OF CONTENTS}

1.0 Project objective.........................

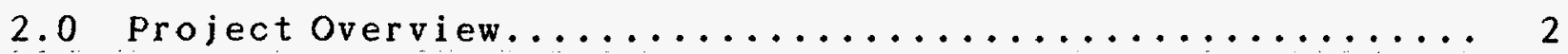

3.0 Project Progress Summary..................... 4

4.0 Project Task Reports....................... 5

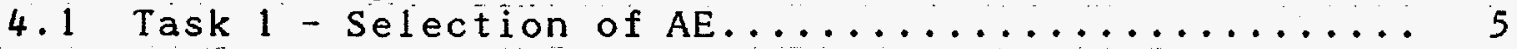

4.1.1 Task Description

4.1.2 Task Status and Activity in Current Quarter

4.2 Task 2 - Conceptual Design "CAT".............. 5

4.2.1 Task Description

4.2.2 Task Status and Activity in Current Quarter 4.2.3 Activity Pianned in next Quarter

4.3 Task 3 - Conceptual Design of Gas Turbine Mods...... 6 4.3.1 Task Description

4.3.2 Task Status and Activity in Current Quarter

4.3.3 Activity Planned in next Quarter

4.4 Task 26 - Combustion System Conceptual Design...... 6 4.4.1 Task Description

4.4.2 Task Status and Activity in Current Quarter

4.4.3 Activity Planned in next Quarter

4.5 Task 4 - Used Gas Turbine Survey.............. 6

4.5.1 Task Description

4.5.2 Task Status and Activity in Current Quarter

4.5.3 Activity Planned in next Quarter

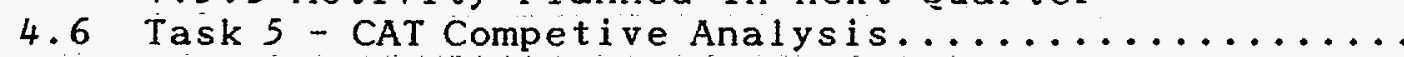
4.6 .1 Task Description

4.6.2 Task Status and Activity in Current Quarter

4.7 Task 6 - CAT Design Fine Tune

4.7.1 Task Description

4.7.2 Task Status and Activity in Current Quarter

4.8 Task 7 - Consortium Packet

4.8.1 Task Description

4.8.2 Task Status and Activity in Current Quarter

4.9 Task 8 - Consortium Meeting Preparation (No Activity)

4.10 Task 9 - Consortium Meeting (No Activity)

4.11 Task 10 - Quarter Iy/Final Reports to DOE..........8

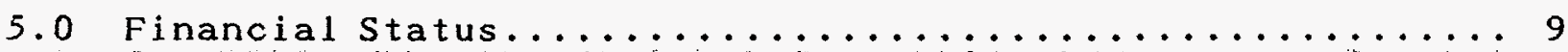

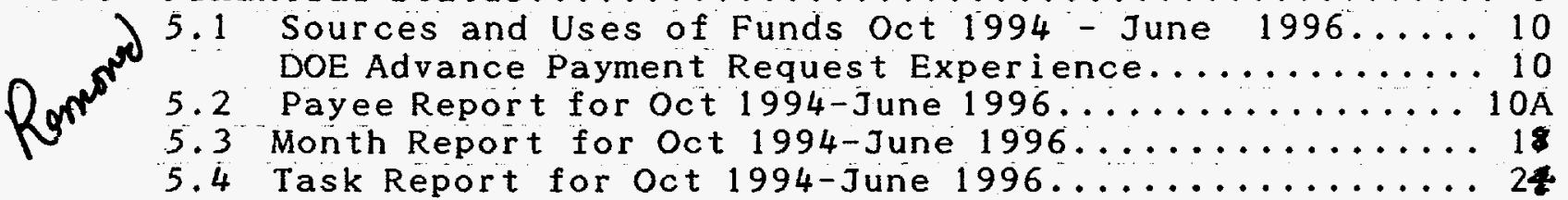

6.0 Current Project Plan..................... 28

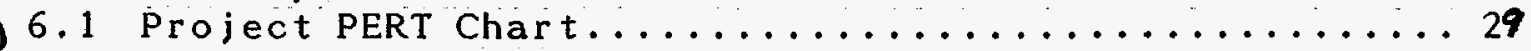

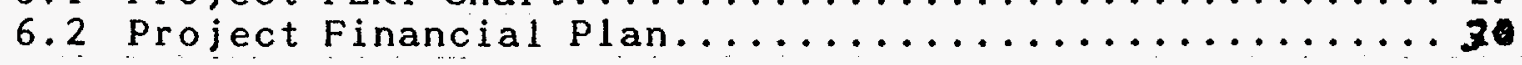




\subsection{Project objective}

The primary objective of this "CAT" project is to complete a conceptual design of this unique new combination of existing technology with cost estimates to show that the "CAT" system offers the economic incentive with low technical risk for a plant to be built which will demonstrate its viability.

The technologies involved in the components of a "CAT" plant are proven, and the integration of the components into a complete plant is the only new developmental activity involved.

Industry and the Federal General Services Administration (GSA), require the demonstration of a "commercial plant" before the viability of a new concept is accepted. To satisfy this requirement the construction of a plant of commerciallly viable size in exess of $15 \mathrm{MW}$ if cogeneration and above 30 MW if all power, is proposed. This plant will produce economical power and heat for the owner. The plant will operate for a full commercial life and continue as an operating demonstration of the viability of the technology, gathering long term 1 ife and maintenance data, all adding to the credibility of the concept. 


\subsection{Project Overview}

The "CAT" System is an innovative new use of existing technology in a unique configuration which will be more cost effective than competitive systems.

In layman's language a Coal Air Turbine "CAT" generates electric power or cogenerates electric power and heat for process use from the burning of coal. Cogeneration, the sequential generation of electricity and heat, is more efficient and economical than their separate production.

Commercial "CAT" power plants with outputs up to $100 \mathrm{MW}$ will be the outcome of this program. The "CAT" plants are expected to be $10 \%$ more cost effective than current state of the art plants with the same output.

The major components of "CAT" plants are an air turbine, a heater of compressed air, a coal combustion system, means to recover waste heat and a steam turbine when appropriate. An air turbine is the same as a gas turbine except that it runs on hot air.

The "CAT" plant burns raw coal in a fluid bed at atmospheric pressure. The air turbine operates on clean compressed air heated ins ide tubes immersed in the fluid bed, thus it is called an "Air Turbine" and the cycle is called a Coal Air Turbine, or "CAT", cycle. Heat is recovered from the exhaust of the air turbine and the coal combustor, to produce steam for process use and / or for driving a steam turbine to generate more power. In a version producing only electric power, the steam is expanded in a steam turbine, condensed and recirculated, instead of the steam being exported for an external use.

Gas turbines now built operate at hotter temperatures than air heaters can produce and if operated at the lower temperatures which air heaters can deliver would be less efficient and more costly. Thus, gas turbines built in the past, which operate with a turbine inlet temperature matching the temperature capability of fluid bed air heaters, are more suitable for "CAT".

Until new gas turbines are again made available for temperatures suitable for air heaters, surplus used gas turbines will be purchased, reconditioned and modified to use hot air from the air heater instead of from combustors.

The operation of fluid bed air heaters has been proven by DOE and others in many tests extending over twenty years. Many metal alloys in many configurations of fluid bed air heaters have been operated for thousands of hours. Suitable alloys and arrangements have been identified. Manufacturers now offer air heaters for the proposed operating conditions with normal commercial warranties. A Circulating Fluid Bed (CFB) combustor will be used to burn the coal. The CFB emits the least sulfur, oxides of nitrogen and particulate material of all the coal combustion systems and meets the most rigorous emission regulations. 
In "CAT" cycles, heat can be recovered from the clean, breathable hot air exhausted by the air turbine for production of steam for coal drying, paper drying, building heat or more power generation.

The following features will result in the production of low cost power by a "CAT" plant:

1. Inexpensive, plentiful coal fuel.

2. Simple efficient coal combustion at atmospheric pressure. (Not pressurized fluid bed or gasification.)

3. Simple emission control by limestone and baghouses.

4. A steam turbine for power generation is unnecessary for cogeneration (but may be used if advantageous).

5. The low cost, low temperature used gas turbines are readily available.

Where coal is competitive, a "CAT" plant will be more economical capacities above $10 \mathrm{MW}$ for cogeneration and for power generation

at capacities above $30 \mathrm{mw}$. 


\subsection{Project Progress Summary}

The project target for a $10 \%$ improvement over existing comparable systems has been achieved with capital cost $8 \%$ less and operating efficiency in excess of $10 \%$.

This is the last progress report for this project. Work on the project is now complete. However, the final project technical report must be assembled and delivered within 90 days of project completion(September 30, 1996). Delivery is planned for December $31,1996$.

A good report is essential for proceding with consortium actions with those having interests in the project going on to commercialization.

As reported previously, all funds provided by DOE have been expended. All work continuing through delivery of the final report on Deccember 31,1996 is being funded by $R$.W. Foster-Pegg. The bank account used during the project will remain open for use in follow on efforts and for deposites from consortium members. 


\subsection{Project Task Reports}

4.1 Task 1 - Selection of $\mathrm{AE}$

4.1.1 Task Description

This task required: 1) Potential Contractor identification, 2) Contractor discussions to determine interest and capability, 3)preparation of an RFP with detailed work scope description 4)Soliciting bids from qualified contractors, 5)Selection of the project AE.

4.1.2 Task Status and Activity in the Current Quarter

Task complete.

4.2 Task 2 - Conceptual Design "CAT"

4.2.1 Task Description

The purpose of this task is to prepare a conceptual design and a cost estimate of a "CAT" plant on a hypothetical site, and to compare the capital cost and cost of power and steam from the "CAT" plant with power produced by alternate power plants on the same site.

Three "CAT" plant configurations will be investigated as follows:

Cycle A - Condensing "CAT"

"Wet" condenser tower (or river) cooling

Steam injection for peaking

Coal fuel.

Cycle B - Cogeneration "CAT"

Back-pressure steam turbine.

Steam export and steam injection.

Coal fuel.

Cycle C - Cogeneration "CAT"

No steam turbine.

steam export and steam injection.

Waste coal fuel.

Deliverables will include:

Site layout drawings

Equipment layout drawings

Estimates of Total Plant Costs

Estimates of the cost of power

Final report

The final report will be the main report developed in the project and wi 11 include information developed/produced in other tasks and by Foster-Pegg Associates. 
4.2.2 Task Status and Activity in the Current Quarter

Cost and efficiency estimates completed and the detailed final report is on schedule.

4.2.3 Activity Planned in the Next Quarter

Task completed.

4.3 Task 3 - Conceptual Design of Gas Turbine Modifications

4.3.1 Task Description

This task requires: 1)Identifying qualified contractors, 2)Discussing the requirement with prospective contractors, 3)Preparing a RFP to solicit bids, 4)Requesting bids, 5) Selecting a contractor

4.3.2 Task Status and Activity in the Current Quarter

The definition of modifications in more detail has been successful in obtaining commitments from contractors for the costing of this work. Revak Turbomachinery Services will do all modifications and Gilbert will do the piping.

\subsubsection{Activity Planned in the Next Quarter} Task is completed.

4.4 Task 26 - Combustion System Conceptual Design

4.4.1 This task was added during the first quarter in order to obtain more detailed design information and more accurate cost estimates on this very vital part of the "CAT" plant. "This would include conceptual designs, performance and cost estimates of the Circulating Fluid Bed and Äir Heater components for the 3 cycles being investigated. Information requested for each cycle includes:

Specifications.

Drawings for layout purposes.

Costs for inclusion in the overall cost estimates.

Performance.

Descriptive Material for inclusion in a report.

This request includes all primary components and auxiliary elements needed for the combustion system.

4.4.2 Task Status and Activity in the Current Quarter

The information from an actual proposal has been successfully used by Parsons for use in finalizing their design and cost estimating.

4.4.3 Activity Planned in the next Quarter

Task is complete.

4.5 Task 4 - Used Gas Turbine Survey

4.5.1 Task Description

The purpose of this task is to survey the availability and cost of used gas turbines. The scope of information desired is as follows:

- Type and number of gas turbines offered for resale by year.

- Type and number of gas turbines resold by year.

- Sources of used gas turbines, by country, by industry.

- Resale price range of gas turbines by type.

- Cost of refurbishing resold gas turbines by type.

- Cost of moving and installing pre-owned gas turbines by type.

- List of vendors offering pre-owned gas turbines. 
- Purchasers of preowned gas turbines.

- Impediments to the use of preowned gas turbines

Insurance, Financial, Utility commissions, etc.

4.5.2 Task Status and Activity in Current Quarter

All required information is complete.

4.5.3 Activity Planned in the next Quarter

Task complete.

4.6 Task 5 - CAT Competive Analysis

4.6.1. Task Description

This task is to provide comparative results to be expected with a "CAT" plant relative to competitive alternative type plants.

4.6.2 Task Status and Activity in the Current Quarter.

This work has been completed with the "CAT' system showing an $8 \%$ improvement in capital cost and an improvement in operating efficiency in excess of $10 \%$.

4.7 Task 6-CAT Design Fine Tune

4.7.1 Task Description

This task is to analyse the estimated cost elements and determine if design changes can be made to reduce cost, and to varify assumptions which impact cost

4.7.2 Task Status and Activity in the Current Quarter

This work has been completed.

4.8 Task 7 - Consortium Packet Materials

4.8.1 Task Description

This task is to identify contacts in Federal Government, State(PA), and Industry(PA) which wi 11 have a vested interest in the installation of a "CAT" system. It includes the production of descriptive materials/letters which will show these contacts what "CAT" systems can do for the state of Pennsylvania and their industries/communities.

4.8.2 Task Status and Activity in the Current Quarter

Through our DOE adviser, David Crouch, we have become aware of an organization in DOE called NICE3(National Industrial Competiveness through Energy/Environment/Economics) which provides matching grants of up to $\$ 400,000$ for projects ready to be launched commercially. This project should qualify but an industry sponsor is needed who would agree to take the project on to commercialization. FPA will make application for a Grant.

To help identify a sponsor, our State Representative, Elinor Taylor, has identified several Pennsylvania Association people and State Personnel who should be able to lead us to interested industry contacts. A letter has been sent to solicit Elinor. Taylor's assistance in arranging a first meeting in Harrisburg. Elinor Taylor has contacted important contacts to initiate follow up.

4.8.3 Activity Planned in the next Quarter Task is complete for the project but will be continued privately

by Richard W. Foster-Pegg. 
Further actions on this effort cannot proceed until there is a good final report in January to use as the basis for soliciting interest.

4.11 Task 10 - Quarterly/Final Reports to DOE 4.11.1 Task" Description

This task is to provide quarterly progress reports and a final report to DOE. As per the current schedules these reports will be as follows:

- 1st Quarter Report for Oct-Dec 1994 due 1/31/95 (Delivered)

- 2nd Quarter Report for Jan-Mar 1995 due 4/30/95 (Delivered)

- 3rd Quarter Report for Apr-Jun 1995 due 7/31/95 (Delivered)

- 4th Quarter Report for Jul-Sep 1995 due 10/31/95 (Delivered)

- 5th Quarter Report for Oct-Dec 1995 due 01/31/96 (Delivered)

- 6th Quarter Report for Jan-Mar 1996 due 4/30/96 (Delivered)

- 7th Quarter Report for Apr-Jun 1996 due 7/31/96 (This report)

- 8th Quarter Report for Jul-Sep 1996 due $10 / 30 / 96$

- Final Report due per new schedule on $12 / 31 / 96$

Per the new project schedule, this project will be completed in September, 1996 so that the Final Report will be due 90 days following the end of the project. 